Virtual Mentor. May 2003, Volume 5, Number 5.

doi: 10.1001/virtualmentor.2003.5.5.cprl1-0305

Clinical Pearl

\title{
Treating Uterine Fibroids
}

\section{Uterine artery embolization is an alternative to a hysterectomy that is safe, effective, and less costly for treatment of uterine fibroids.}

\author{
Audiey Kao, MD, PhD
}

Uterine leiomyomas or fibroids are benign tumors of the uterus that develop in up to 25 percent of women [1]. Significant morbidity from uterine fibroids include prolonged or heavy menstrual bleeding, pelvic pressure or pain, and, in rare cases, reproductive dysfunction [2].

Surgery has been the mainstay of fibroid treatment, and in fact, uterine fibroids are the most common indication for hysterectomies. Treatment with gonadotropin-releasing hormone agonists, alone or in combination with more conservative surgical treatments, such as myomectomy or myolysis, are also used.

More recently, patients have a less invasive option than hysterectomy-uterine artery embolization (UAE). Studies have found that UAE is safe, effective for the treatment of fibroids and less costly than a hysterectomy [3-7]. Some patients, however, may not be good candidates for UAE such as patients who:

- Have extremely large fibroids (fibroid volume is generally reduced by no more than 50 percent),

- Have fibroids that compress the bladder (uterine arterial embolization in these cases may not provide sufficient symptomatic relief),

- Wish to bear children in the future.

UAE interrupts the uterine blood supply by injecting agents such as polyvinyl alcohol articles. As seen in Figure 1, the pre-embolectomy angiogram shows the uterine arterial blood flow (arrows designate the uterine arteries), while in Figure 2, the post-embolectomy angiogram reveals no further blood flow through the right or left uterine arteries.

\begin{tabular}{|l|l|}
\hline \multicolumn{1}{|c|}{$\left[\begin{array}{l}\text { Figure 1 } \\
\text { pre-embolectomy angiogram }\end{array}\right.$} & Figure 2 \\
\hline
\end{tabular}

Side effects and complications of UAE include:

- Infection (in approximately 2 percent of cases),

- Irregular menses or amenorrhea (in approximately 10 percent of cases),

- Partial bowel obstruction (rare).

\section{References}

1. Buttram VC, Reiter RC. Uterine leiomyomata: etiology, symptomatology, and management. Fertil Steril. 
1981;36:433-445.

PubMed Google Scholar

2. Stewart EA. Uterine fibroids. Lancet. 2001;357:293-298.

View Article PubMed Google Scholar

3. Walker WJ, Pelage JP. Uterine artery embolization for symptomatic fibroids: clinical results in 400 women with imaging follow up. BJOG. 2002;109:1262-1272.

View Article Google Scholar

4. Payne JF, Haney AF. Serious complications of uterine artery embolization for conservative treatment of fibroids. Fertil Steril. 2003;79:128-131.

View Article PubMed Google Scholar

5. Pron G, Cohen M, Soucie J, Garvin G, Vanderburgh L, Bell S. The Ontario uterine fibroid embolization trial. Part 1. Baseline patient characteristics, fibroid burden, and impact on life. Fertil Steril. 2003;79:112-119. Google Scholar

6. Pron G, Bennett J, Common A, Wall J, Asch M, Sniderman K. The Ontario uterine fibroid embolization trial. Part 2. Uterine fibroid reduction and symptom relief after uterine artery embolization for fibroids. Fertil Steril. 2003;79:120-127.

View Article PubMed Google Scholar

7. Al-Fozan H, Dufort J, Kaplow M, Valenti D, Tulandi T. Cost analysis of myomectomy, hysterectomy, and uterine artery embolization. Am J Obstet Gynecol. 2002;187:1401-1404.

View Article PubMed Google Scholar

The viewpoints expressed on this site are those of the authors and do not necessarily reflect the views and policies of the AMA.

(C) 2003 American Medical Association. All Rights Reserved. 